\title{
CENTRO DE ESTUDOS FRANCO DA ROCHA
}

Sessão ordinaria - 27, Novembro, 1942

PRESIDENTE - DR. MARIO YAHN

Com a presença de representantes de outras entidades científicas, dos associados e de numerosos convidados, este Centro de Estudos inaugurou suas atividades com a conferência do Dr. Edgard Pinto Cezar, diretor do Hospital Central de Juquerí. Esta conferência - Assistência aos doentes mentais no Estado de São Paulo — abordando assunto de grande interesse médico e social, vem publicada na integra neste numero de ARQUivos DE NEURO-PSIQUIATRIA.

$$
\text { Sessão ordinaria - 9, Desembro, } 1942
$$

Valor semiológico do angulo da conzergência. Apresentação de um aparelho do autor. Dr. J. Candido da Silva.

Trabalho apresentado à Secção de Neuro-Psiquiatria da Associação Paulista de Medicina, na sessão de 9 de Fevereiro de 1943.

Influência da menstruação sobre a incidência das crises convulsivas em epilépticas. Drs. J. O. Rios e J. P. G. d'Alambert.

Os AA., após analizar a literatura a respeito, estudam, em 104 casos pessoais, a influência da menstruação sobre a incidência das crises convulsivas e referem-na pouco nítida. Nos casos de mạior influência são verificadas quais as condições mais favorecedoras (gravidade do caso, idade, etc.). 
Sessão ordinaria - 20, Janeiro, 1943

Considerações sobre o livro de Maurice Dide - L'Hysterie et l'evolution humaine. Dr. C. Trapè.

Contribuição da odontologia no tratamento dos psicopátas. J. F. Varela (udontologista).

O A. teceu comentários sobre os fócos sépticos da cavidade bucal e o papel importante que os mesmos desempenham na eclosão e na manutenção de certas doenças mentais. A seguir propõe medidas e uma norma de trabalho para o combate a esses fócos, o que iria não só contribuir para se estudar a sua importância médica, como para resolver o problema entre os doentes internados no Hospital de Juquerí, aliás em grande número.

Espasmo da convergência com espasmo da acomodação no diagnóstico da encefalite epidêmica. Dr. J. Cândido da Silva.

Estudando o valor dos síndromos neuro-oculares post-encefalíticos, apresenta uma doente portadora de um síndromo complexo cerebelo-piramidal, na qual o diagnóstico de escleróse em placas que fora feito anteriormente poude ser afastado pela anamnése minuciósa que evidenciou um surto agudo pregresso de encefalite letárgica e um síndromo neuro-ocular caracterizado por espasmo da convergência e da acomodaçãa. A respeito desses sintomas. $\because$ A. discute sua fisio-patologia e expõe a sua semiologia.

Sessão ordinaria - 17, Fesereiro, 1943

No expediente foi lida uma carta da viuva do Prof. Franco da Rocha a qual, em resposta a um oficio que the fora enviado pela diretoria deste Centro transmitindo-lhe a noticia de sua fundação, agradeceu em nome da família do saudoso mestre e comunicou a deliberação de doar à bibliotéca do Hospital de Juquerí os livros que pertenceram ao fundador deste hospital.

Tumor do lobo frontal. Estudo anátomo-clinico. Dr. Paulo Pinto Pupo.

Tumor do lobo frontal direito, comprometendo secundariamente o esquerdo, que evoluio sem qualquer sintoma focal. Sómente no período final surgiu o quadro de hipertensão intra-craniana. $O$ exame histo-patológico mostrou tratar-se de um astrocitoma com degeneração maligna. Existia grande c difuso edema encefálico que explicava o síndromo de hipertensão intracraniana. Depois de fazer unıa resenha geral da sintomatologia dos tumores do lobo frontal, o autor procura explicar porque este caso se apresentou sen qualquer perturbação neurológica ou psiquiátrica.

Considerações em torno de tres casus suspcitos de néo-formação intra-craniana. Dr. Mario Yahn.

Tratava-se de tres doentes nos quais os exames clínico, radiológico, humoral e neuro-oftalmológico indicavam a possibilidade da existência de néoformação intracraniana. $\mathrm{Em}$ un deles, com um síndromo epiléptico evoluindo la 15 anos, o exame do liquido céfalo raquidiano forneceu dados que levavam ao diagnóstico de cisticercose encefálica. O segundo, com uma hemiplegia de evolução progressiva, foi encaminhado para a intervenção cirúrgica, tendo 
sido encontrada aracnoidite opto-quiasmática. No terceiro foi tentada, sem resultado, a radioterapia profunda. A proposito destes casos nos quais não foi possivel um diagnóstico de certeza, o autor discute a patogenia dos sintomas e salienta as dificuldades com que se defronta, às vezes, o neurologista para estabelecer o diagnóstico e prognóstico.

S’essâo ordinaria - 24, Março, 1943

Sobre uma noża classificação de doenças mentais. Drs. Edgard Pinto Cezar, Francisco Tancredi e Darcy Mendonça Uchôa.

Em nome da comissão encarregada de elaborar uma classificação para doenças mentais mais de acordo com o progresso da ciência, o Dr. Darcy Mendonça Uchôa apresentou a seus colegas, com o fim de coletar sugestōes, o ante-projeto elaborado. E' grande a dificuldade para a elaboração de uma classificação científica das doenças mentais. Muitas delas têm seus fatôres etiológicos, patogênicos e psicológicos ainda desconhecidos. Por outro lado, a anatomia patológica destas doenças ainda não é segura. De tudo resulta, que, muitas vezes, o clínico defronta-se com quadros sindrômicos que muito pouco o orientam para a compreensão da estrutura das psicóses. No estado atual de nossos conhecimentos não é possivel adotar um critério unívoco que satisfaça, para uma tal classificação, as exigências de um verdadeiro niétodo científico. Dest'arte os autores foram obrigados ao ecletismo para conseguir um agrupamento prático das desordens mentais para fins terapêuticos e estatísticos. Para tanto modificaram a classificação vigente, acrescentando-lhe novos grupos e modificando-lhes, por vezes, a designação, procurando integra-los nas modernas aquisições da psiquiatria atual. $O$ ante-projéto será discutido em sessão ulterior com as emendas que forem.sugeridas.

Considerações sobre a cletrochoqueterapia. Dr. Paulo Ferreira de Barros.

São expostos os conhecimentos adquiridos com a prática do eletrochoque no 5. Pavilhão de Mulheres do Hospital Central de Juquerí. São estudadas as questões relativas ao preparo do doente, à colocação dos eletrodos, à técnica do eletrochoque $\mathrm{e}$ à dosagem da corrente. São postos em relevo os pontos em que a sintomatologia da crise provocada pela corrente elétrica difere da crise cardiazólica. Estudando as manifestações post-convulsivas, são referidas as alterações neurológicas, as modificações da pressão arterial, o aumento da glicemia e da leucocitóse. O tratamento é feito por dois métodos: o simples em séries de 20 choques e o especial em séries de 40 choques, sendo 2 ao dia. São relatados os resultados obtidos e as indicações, vantagens e complicações do eletrochoque.

\section{Sessâco ordinaria - 16, Abril, 1943}

Estado esquizofrênico de fórma hebefreno-catatônica resolvido por um tratamento combinado: psicanalítico $c$ medicamentoso. Nova técnica psicanalítica empregada. Dr. Paulo Lentino.

Para ser empregada nos casos de psicóses e neuróses em que é impossivel manter conversação com os doentes, é proposta uma nova técnica psicanalítica. Consiste no estudo da personalidade pré-psicótica ou pré-neurótica, 
dos mecanismos afetivos que poderiam ter condicionado as reações mórbidas, das atitudes espontaneas ou provocadas do doente. Depois de se ter preparado bem o terreno, promover-se-á uma acareação entre o doente e as pessoas da família contra os quais haja ressentimentos ou constrangimentos, tudo na presença do médico que servirá de interprete e mediador. Deflagra-se, assim, intensa ab-reação cujos resultados são comparaveis ao primitivo método catártico de Breur-Freud, dando-se a descarga em massa das emoções recalcádas: é a técnica da acareação ou do desnascaramento diréto. No caso de esquizofrenia que ilustra o trabalho, com intenso negativismo e quasi completo nutismo e no qual os tratamentos medicamentosos não surtiram efeito util, foi conseguida uma remissão completa e duradoura (pelo menos 3 anos sem recidiva), após apenas uma acareação com a mãi da paciente, solucionando-se uma situação edipiana e narcísica que se tornara intoleravel, condicionando a reação esquizofrènica. São referidos, ligeiramente, tres casos de reações neuróticas de situação, resolvidos facilmente depois de uma acareação com os parentes. A nova técnica pode ser empregada para solucionar situações de neuróticos e psicóticos, embora no tratamento de fundo se empregue a técnica freudiana. 